Social marketing, sustainable tourism and Small/Medium size Tourism

Enterprises: Challenges and opportunities for changing guest behaviour

D. Scott Borden 1,2

Tim Coles ${ }^{1}$

Gareth Shaw ${ }^{1}$

1 University of Exeter Business School. Streatham Court, Rennes Drive, Exeter, Devon. EX4 4 PU, United Kingdom

2 Department of Environment and Sustainability, Western State Colorado University. Kelley Hall 240, 600 North Adams Street, Gunnison, CO 81231, United States of America. 


\title{
Social marketing, sustainable tourism and Small/Medium size Tourism Enterprises: Challenges and opportunities for changing guest behaviour
}

\begin{abstract}
This paper investigates the impact on the guest experience of initiatives promoting water efficient behaviour in small-/ medium-sized enterprises (SMTEs) offering tourism accommodation. Interviews with 16 SMTE managers revealed businesses were unable to incorporate many initiatives previously examined in the literature due to the small size of their businesses. In the interviews, however, they contributed three new ideas not previously examined in existing sustainable tourism dialogues. A subsequent questionnaire $(n=408)$ was administered to potential guests to better understand their water use behaviour, explore how initiatives might impact their accommodation experience, and to assess guest reactions to social marketing messages. Eight initiatives and five messages were tested. Cluster analysis revealed three distinct water user segments with one cluster showing the greatest promise for targeting to increase return on investment. Guests reported the highest positive impact on their experience from initiatives SMTEs stated were not operationally viable. This may indicate that larger firms have a competitive advantage over SMTEs if applying social marketing to change guest behaviour. However, the study found that two of the new initiatives suggested by SMTE managers as more appropriate to their businesses, would be viable in engaging guests and at acceptably low costs.
\end{abstract}

\section{Keywords:}

Social marketing, SMTE, water efficiency, behaviour change, tourism accommodation

\section{Introduction}

The tourism industry is a growing contributer to climate change and the degradation of resources (Scott, Peeters \& Gössling, 2010). One such vital resource is potable water where the industry has substantial impacts on fresh water systems (Gössling, Peeters, Hall, Ceron, Dubois, Lehman \& Scott, 2012). Gössling, Hall and Scott (2015) further acknowledge that the tourism 
industry generally increases per capita water consumption per individual; shifts water consumption between continents and regions; concentrates water use during certain times of the year; can cause injustices where visitors have greater access to, and use larger amounts of water than host peoples; and can negatively impact water quality through sewage discharge.

One area of growing interest is how social marketing may be applied within this sector. Social marketing is "the adaptation and adoption of commercial marketing activities, institutions and processes as a means to induce behaviour change in a targeted audience on a temporary or permanent basis to achieve a social goal" (Dann, 2010, p.151) and has been applied to a wide range of tourism issues (Hall, 2014). Their potential to contribute to sustainable tourism has been acknowledged, not least by encouraging pro-environmental behaviours among visitors (Dinan \& Sargeant, 2000). However, their application specific to small-/ medium-sized Tourism Enterprises (SMTEs) has received little attention to date.

This paper investigates how initiatives encouraging water efficient behaviour among guests, developed through the process of social marketing with smaller firms, may impact the guest experience. Distinct challenges and opportunities are described and implications for both practitioners and researchers are discussed. To better understand the relationship between SMTEs and social marketing, a literature review is presented and results from two stages of empirical research are discussed. The first stage, interviews with managers of SMTEs, examined the willingness and ability of participating businesses to carry out initiatives within their accommodation. Managers were also asked to describe or create new initiatives not previously examined in the academic literature. In stage two, a questionnaire was administered to potential guests aiming to better understand their water use behaviour and how newly described initiatives may impact their experience. 


\section{Literature review}

No consensus on the key points that define the social marketing process exists, as evidenced by variations within the literature (e.g. French, Blair-Stevens, McVey \& Merritt, 2010; Corner \& Randall, 2011; Truong \& Hall, 2013; Shaw, Barr \& Wooler, 2013). However, there are a number of commonly required stages highlighted in the literature: 1. Define behavioural goal(s); 2 . segment the audience; 3. use a marketing mix; 4. consider the importance of the exchange; and, 5. incorporate balance between competing factors for behaviour.

Expanding on these points, when defining behavioural goals, it is important to target end point behaviours (McKenzie-Mohr, Lee, Shultz \& Kotler, 2012) as social marketing aims to promote measureable behavioural change and not just change in attitudes, awareness or beliefs (Truong \& Hall, 2013). Similarly, segmenting audiences is a common marketing technique (Mazzocchi, 2008) used to understand unique desires and barriers expressed by groups of individuals and then developing tailored initiatives for those in each group (Shaw et al., 2013). While other research efforts have focused on expanding and redefining the marketing mix in the social marketing literature (Gordon, 2012), it is used during the process to define where, what and how to present initiatives to targeted segments (Andreasen, 2002). Next, tangible items (e.g. financial incentives, products) or intangibles (e.g. increased recognition within a peer group, regional pride) are exchanged for the desired change in behaviour based on the segments' unique motivations (French et al., 2010). All factors competing for a segment's responsiveness and willingness or ability to reach the defined behavioural goal(s) are considered and minimized (Shaw et al., 2013). Together these stages make up the foundation of the social marketing process which guided much of this current research and will be revisited in the discussion section of this paper.

This process, or parts of it, have previously been applied in research examining water consumptive behaviours within tourism accommodation. For example, towel and linen reuse programmes in tourism accommodation have been identified as a seminal example of applying 
social marketing efforts in tourism studies (McKenzie-Mohr, et al., 2012). Work by O’Neill, Siegelbaum and The RICE Group (2002) represent the first research into this topic, concentrating on the Seattle hotel industry. Using two hotels as case studies, they identified a range of factors encouraging businesses to save water and implement towel reuse programmes. Similarly, Goldstein, Cialdini and Griskevicius (2008) marked the first research into guest behaviour in this area, encouraging a plethora of similar work. Their research highlighted the ability to change guest behaviour through changing in-room messaging and found signage incorporating localized descriptive norms (i.e. 'most guests in this hotel room participate in the programme') significantly increased participation in towel reuse schemes. This research was followed by Schultz, Khasian and Zaleski (2008) who replicated these studies adding a component of residents living in condominiums and found a combination of injunctive norms (what an individual feels they should do in a context) and descriptive norms (going along with everyone else) significantly increased participation. In addition, Mair and Bergin-Seers (2010) tested the need for informative texts to articulate the importance of reusing towels against providing incentives. They found participation rates significantly increased with the addition of information and not incentives.

Building in part on previous efforts, Shang, Basil and Wymer (2010) applied a social marketing aspect to messaging, finding a statement of previously donating savings to a charity increased both participation and loyalty, while messages stating participation would provide savings for the business decreased participation and loyalty. They therefore recommended retrospective donations and use of personalized messages linked with the company logo to deter guest scepticism. In a slightly different approach, Blose, Mack and Pitts (2014) tested the concept of loss aversion, (individuals are more likely to act to not lose something rather than gain the same amount) finding a significant increase in towel reuse scheme participation when loss aversion was added to messaging. These studies would be complimented by Reese, Loew and Steffgen (2014) whom applied similar effort to hotels in Europe, finding altering messaging was also effective in changing guest behaviour in international destinations. 
Other research in this area has focused on a variety of related topics. For example, BacaMotes, Brown, Gneely, Kennan and Nelson (2013) tested the impact on behaviour from guests making written, verbal and/or public commitments to participate in reuse programmes. They found wearing a pin, as a form of public commitment, combined with a written commitment increased participation above participants making no commitment and those making only written commitments. More general findings and examples from practitioners are reported in Gössling, et al. (2015), including the suggestion that seasonality is viewed as a potential variable to guest participation in saving water, as well as locality to certain activities (e.g. swimming pools and the ocean). Finally, in an effort to better understand messages currently being used by tourism accommodations to encourage guest participation in towel reuse schemes, Lee and Oh (2014) examined a diverse sample of messages from hotels and found a complexity of theory (such as those highlighted previously) already applied in practice.

This review has concentrated primarily on reuse schemes as this has been the primary focus in the literature to date. However, participation in these programs is only one of many behaviours related to water consumption. Significantly, participation in reuse schemes and general water use behaviour (e.g. fitting low consumption showers and taps) have been found to be driven by different motivations and may therefore require varying interventions (Schultz et al., 2008). Furthermore, some research suggests changing water use behaviour may prove difficult as these behaviours are embedded in the social context of comfort, convenience and cleanliness (Shove, 2003) and guest behaviour in tourism accommodation is driven by hedonistic motivations (Miao \& Wei, 2013). Therefore, clearly, a wider range of initiatives and a deeper understanding of the topic are needed to capture the complexities of water reduction within this context. This review has also highlighted some interconnected roles of both guests and managers in saving water, where initiatives (e.g. messages, commitments, incentives, etc.) encouraging guests to save water must first be adopted by and then effectively managed through businesses. 
Since businesses are an integral part of this relationship, it is important to understand why they engage in such environmental initiatives. Here we focus on SMTEs as they dominate the sector globally and their importance in generating (and reducing) environmental externalities from tourism has been widely acknowledged (Font, Garay \& Jones, 2014; Coles, Zschiegner \& Dinan, 2014). The motivations for engaging in pro-environmental behaviour vary between firms, though much of the previous literature has stated larger firms engage in Corporate Social Responsibility (CSR) to justify the business case (Font et al., 2014). However, smaller firms show both different motivations and barriers to engaging with CSR to those of larger firms (Morsing \& Perrini, 2009). For example, Fassin, Van Rossem and Buelens (2011) find decision-making in smaller firms is often not linked to profit and is instead an extension of the owner-manager's attitudes. Compared to larger firms, smaller firms may have the advantage of adopting or changing sustainable practices more quickly (Condon, 2004). However, their disadvantages have been described as possessing less capital, lacking information on market opportunities, having higher risk exposure, missing structured management systems and not engaging in long term planning (Ateljevic \& Doorne, 2000; Dewhurst \& Thomas, 2003). Lack of information may also include exposure to academic and practitioner findings and recommendations, though Fassin et al. (2011) claim smaller firms commonly have a strong understanding of CSR issues without knowing specific theory.

More recently, Font et al. (2014) have expanded upon the current understanding of the motivations for SMTEs to engage in CSR, finding three distinct types of owners-managers based on their motivations to be sustainable. The first were competitiveness driven firms which reported the fewest efforts to be sustainable and were motivated by the business case. Next, firms driven by legitimization were motivated by social capital, a desire to please other stakeholders to gain value from their peers, and reported a variety of efforts. And finally, owner-managers driven by lifestyle and values reported the highest amount of CSR related efforts. 
Efforts to engage in CSR also include interacting with and encouraging guests to act responsibly. However, work by Coles, Warren, Borden and Dinan (2016) describe a desire by SMTEs to avoid engaging in changing guest behaviour due to a fear of online negative comments. Font, Elgammal, and Lamond (2016) find similar patterns, reporting tourism accommodation in their study only communicated $30 \%$ of their efforts to their guests through their websites. They offer the term 'greenhush' to describe this phenomenon where businesses communicate only the least contentious issues to display their efforts. These studies highlight the delicate balance businesses, including SMTEs, have with communicating their environmental efforts to guests. Further emphasising the importance of this issue, Coles et al. (2016) suggest avoiding promoting behaviour change with guests may actually increase unsustainable actions by indicating to customers that hedonistic behaviour is acceptable.

To better understand this delicate balance of engaging with guests, here, we investigated a wide range of behaviours and initiatives aiming to promote a diversity of water efficient actions (e.g. turning off taps, participating in schemes, taking shorter showers, etc.) with both managers and potential guests. The results are recommendations to practitioners and researchers on changing guest behaviour in SMTEs, informed through a multi-stakeholder approach, while attempting to minimize negative impacts on the guest experience.

\section{Methods}

Research was conducted through mixed methods as Molina-Azorin and Font (2016) identify that within sustainable tourism research, this approach may increase reliability in relation to social desirability bias, stakeholder comparisons and transdisciplinarity. Social desirability bias refers to participants wishing to answer questions the 'right' way. As such, two stages of data collection were conducted. In stage one, 16 semi-structured interviews with managers of SMTEs in South West England examined the nature and effectiveness of potential behaviour change initiatives within tourism accommodation. South West England was selected for this 
study as it is a primary UK holiday destination with a diversity of SMTEs business types (Coles et al., 2016). In stage two, a questionnaire was administered to potential guests examining general water behaviour and how initiatives, identified in stage one, might impact the guest experience.

\section{Stage One: Semi-Structured Interviews with SMTEs}

Semi-structured phone interviews were conducted with 16 tourism accommodation managers to better understand how they may encourage guests to use water efficiently. Questions evolved through dialogue with participants, as is standard for semi-structured interviews (Barbour, 2013). General themes were established after review of findings from O'Neill et al. (2002) and four areas for discussion were used: water management within the accommodation; barriers to changing guest behaviour; feedback on initiatives previously investigated in the academic literature: and, managers' ideas for initiatives to promote guest water efficient behaviour. Specifically, when discussing feedback on initiatives previously examined in the academic literature, managers were asked about the viability of implementing these efforts into their operations: donations to charity (Shang et al., 2010); money-off vouchers (Shang et al., 2010); water saving technologies (O'Neill et al., 2002); providing a personalized measurement of water use to each guest; and, messaging (e.g. Goldstein et al., 2008; Schultz et al., 2008) using psychological theories (e.g. loss aversion, localized descriptive norms and technical information on the subject).

Managers were selected by convenience from a list of customers from the area's water company (South West Water). This data set was chosen because it represented all SMTEs receiving mains water in South West England. Figure 1 displays accommodation types represented by over 8,500 South West Water customers. The data does not indicate size of the accommodation, however, Coles et al. (2016) observe that the South West of England is dominated by micro, small and medium tourism accommodation businesses. 
[Insert Figure 1 near here]

In an effort to collect a representative data set, South West Water customer data was stratified by business size and type of accommodation. As defined by Storey (1994), micro-businesses have 0-9 Full Time Equivalent (FTE) employees; small businesses, 10-49 FTE; and, medium businesses, 50-100 employees. Businesses, where contact information was available, within each stratified grouping were emailed and interviews were held with the first respondents until saturation in findings was determined. The final sample size represented 16 managers: Hotels (3); B\&Bs (3); self-catering (7) and tent/caravan (2). The sample was an effort to survey a group of businesses indicative of the diversity within the region, though due to convenience sampling, no claims are made that it is representative. A full list of interviews and key characteristics of each accommodation are presented in Table 1. Transcriptions were coded by theme and key words. Codes were allowed to be 'in-vivo' (Barbour, 2007), enabling managers to define relationships with their own words. Labels representing each business have been used to preserve anonymity.

[Insert Table 1 near here]

\section{Stage Two: Guest Questionnaire}

Questionnaires were administered to individuals living in England and Wales concerning their water behaviours and the impact of potential initiatives on their experience when in tourism accommodation. Similar questionnaires have been used to better understand intentional water use behaviour in tourism accommodation previously by Shang et al. (2010) and Blose et al.

(2014). Here, participants from England and Wales were combined as their water regulation is conducted by the same national organization: OFWAT. Scotland, Ireland, Northern Ireland and 
all international destinations were excluded as they have different regulatory standards which may affect metering rates and behaviour. A market research company was hired to administer questionnaires as followed out in similar work by Dolnicar and Grün (2009) and Shang et al. (2010). Market research companies maintain internet panels representative of the UK's national census profile. Participants in these panels give their permission to be contacted for the purpose of research. Participants receive a small compensation based solely on the length of completed questionnaires. Within the panel, an on-line questionnaire was sent to randomly selected participants between the dates of August $28^{\text {th }}-30^{\text {th }}, 2015$. These dates were chosen to coincide with the end of a major holiday season in the UK, aiding participants in recalling more recent behaviour whilst in tourism accommodation.

To further aid in recalling past behaviour, potential participants were not able to complete the survey if they had not stayed in tourism accommodation in England or Wales in the past six months. For those participants able to complete the survey (n=408), compulsory response questions collected information relating to: demographic and travel characteristics; the extent to which water consumptive services impacted their last booking decision (Cronbach's alpha 0.834); water behaviours in tourism accommodation (Cronbach's alpha 0.607); impact of initiatives aiming to reduce water use on their experience (Cronbach's alpha 0.816); the extent to which messages asking to help reduce water would encourage efficient behaviours (Cronbach's alpha 0.837); and, the physical location where messages would most impact their behaviours (Cronbach's alpha 0.832). According to Drasgow (1984), a Cronbach's alpha score of 0.6 is sufficient for exploratory research and therefore all scales were considered valid.

The wording of water related behaviours measured in this research were obtained from previous studies to allow for comparison (DEFRA, 2009; Miao \& Wei, 2013; UKWIR, 2014). A small pilot survey ( $n=21$ ) was used to ensure wording clearly conveyed the researchers' intentions and some questions were later reverse coded to aid in interpreting results. SPSS 
version 22 was used to analysis the data. Analysis showed data was generally linear but nonparametric tests were determined to be most appropriate.

Segmenting the audience is an important step in social marketing campaigns where the aim is to better understand and then target specific groups most effectively (French et al., 2010). To accomplish segmentation, the statistical method of cluster analysis is routinely used. Cluster analysis applies numerous steps of combining observations and placing them together into 'heterogeneous groups consisting of homogenous elements' (Franke, Reisinger \& Hoppe, 2009: 273).

Cluster analysis was performed to identify segments with homogenous water efficient behaviour within the tourism accommodation. In some previous efforts (e.g. DEFRA, 2009; UKWIR, 2014; Shaw et al., 2013), both attitudes and behaviours have been used for clustering. This method assumes there is a degree of translation from attitude to behaviour. To avoid this assumption, only behaviours were used to segment water users. To determine the number of behaviours to use during cluster analysis, recommendations from Dolnicar, Grün, Leisch and Schmidt (2013) were used. Through a cluster analysis simulation study, Dolnicar et al. (2013) analysed data with known structure to determine appropriate sample size. Under all simulations, a ratio of 70:1, sample size to number of clustering variables, proved to be adequate for maintaining the known structure. To ensure best practice, this ratio was applied herein. With a sample size of 408 , five behaviours within the tourism accommodation were used.

Prior to the final analysis, exploratory cluster analysis was conducted. During exploratory cluster analysis, Hair, Black, Babin and Anderson (2011) recommend clustering variables with a range of methods and analysing results prior to determining the final protocol. Through this process, five behaviours were chosen based partly on their high variation between individuals, as recommended by Hair et al. (2011), and also through trial and error with the goal of discovering stable and valid clusters. The five behaviours meeting these criteria were: 'I take 
efficient showers'; 'I shower instead of bath specifically to save water'; 'I take one or less showers/baths per day'; 'If offered, I participate in towel reuse schemes'; and, 'I turn off the tap when brushing teeth.' All behaviours were measured on the same five point Likert scale and the categorical data were standardized.

In the final analysis, a two-step procedure was applied where hierarchical cluster analysis determined the number of clusters and non-hierarchical cluster analysis (K-means) was used to place individuals within the determined number of clusters. This two-step procedure is recommended by Mazzochi (2008) and Hair et al. (2011). During hierarchical clustering, Ward's method was used as it creates more similarly sized groups (Hair et al., 2011) and has been applied in similar types of research (e.g. Barr, Shaw, Coles \& Prillwitz, 2010; Coles et al., 2014). Squared Euclidean distance was applied as the measurement between observations as recommended for Ward's method by Hair et al. (2011). No single 'stopping rule' has been found to best determine the number of clusters (Mazzocchi, 2008). Here the dendrogram and percentage change in heterogeneity between clustering groups, using a calculated agglomeration coefficient, were used and a three or four cluster solution emerged as most valid. After exploring both outcomes, a three cluster solution was deemed most stable and valid. K-means cluster analysis was then run with a three cluster solution and was considered stable with only $3.6 \%$ of individuals changing cluster positions between the hierarchal and nonhierarchal test. Hair et al. (2011) classify cross tabulations of under $10 \%$ as very stable. All five behaviours used for clustering were significantly different between clusters.

\section{Results and analysis}

\section{Stage One: Semi-Structured Interviews with SMTEs}

Sixteen managers participated in semi-structured interviews covering the topics of water management by the accommodation; barriers to changing guest behaviour; feedback on 
initiatives previously investigated in the academic literature: and, their ideas for initiatives to promote guest water efficient behaviours. The sample contained both managers that actively managed their water and water use by their guests and those that did not, providing a diversity of feedback for this study. Perhaps surprisingly, responses were mostly consistent, transcending both type and size of tourism accommodation. Since type of accommodation varied greatly while size remained fixed to SMTEs in this study, this may further suggest SMTEs collectively have unique needs and contexts different to those of larger firms.

\section{Barriers and Drivers to Changing Guest Behaviour}

Managers were asked what barriers exist for implementing initiatives aiming to change guest behaviour. Overwhelmingly, guest satisfaction was most frequently identified with one managers stating: 'If it was something that saved water but made the guest experience worse, frankly we wouldn't be doing it. When we focus on water we very much focus on how to help the environment without giving them a worse holiday (SC4).' In this context, the guest experience was principal.

Costs of implementing initiatives were the second most frequent response. This quote emphasises the general consensus of needing to preserve the guest experience and lower costs:

'You need something that makes their experience better, saves water and saves us money if you want it to be successful (SC2).'

Other stated barriers of note were a belief that managers had already implemented all possible interventions; low levels of trust in suppliers and information from distributors; a desire to minimize messaging to not overwhelm guests; basic guest needs; and, facility limitations.

This general consensus on barriers was in contrast to stated drivers. When asked about what would motivate managers to implement behaviour change initiatives they reported a 
variety of different answers. Some stated it was part of their personal values while others commented it made them feel a part of a group of concerned business owners. A smaller group identified the need to reduce costs.

\section{Previously Examined Initiatives}

All participants conceded they had no prior knowledge of previous academic findings on the topic of encouraging behaviour change among guests. However, they stated a high interest in the topic, such as in this quote from one participant:

'.... I think it is something I should definitely see. I think there is a particular skill in putting that wording together and we would be very interested in seeing information on that (H3).'

Previous research, highlighted in the literature review of this paper, was reviewed with each manager. Managers were asked about the viability of each initiative at their establishment. Generally, managers showed lower interest in initiatives with higher financial cost and time investment. In particular, many managers stated donations to charity and voucher-off coupons would be too costly and implementing systems to account for guest participation were too complex for their small businesses. One manager stated, 'no, personally I think that would take a lot of man-hours...' (BB3), while another remarked, '...but we just don't have the capital to make something like that work long term' (SC7). Providing personalized measurements was considered too invasive into the guest experience and technology able to measure water usage within each room was cited as a barrier. Costs and the potential to disrupt the guest experience were frequently cited as reasons for not using technological implementations such as waterless urinals in common areas and grey water recycling devices. While these barriers varied from technology to technology, this general theme emerged. 
Managers showed the highest interest in providing messages promoting water efficiency as an initiative. One participant explained: 'Yes, we would be very interested in seeing the messaging research and are currently doing only verbal requests. We have been thinking about messaging because our costs are high (BB1).' This was due to a general belief that messaging to guests as an initiative had a low cost and low impact on the guest experience as one managers stated: 'They sound very subtle but effective. Doesn't sound intrusive at all but could have a big change (T2).'

However, when specific research on messaging was reviewed, managers were uneasy with the wording of previous efforts: 'That sounds too boring, we need something more fun, they are on holiday after all (SC7).' They also cautioned about the tone, length and amount of messaging: 'We work really hard for them so they don't need to worry about it. We aren't expecting them to come on a week-long environmental lecture (SC2).' Instead they offered: 'It is about focusing on the do's and not the don'ts. You have to engage with guests (SC1).' This feedback lead to a discussion concerning the ideas managers had for further engaging guests.

\section{New Contributions from SMTEs}

Managers were asked to create or explain existing solutions to reduce water use in tourism accommodations that had not been previously researched. Since interviews were completed at different times, they were also presented with the previous ideas by managers in prior interviews and asked to comment on them. In this way the later interviews were able to have a process of review, and in some cases recommended enhancements of their peer ideas. Perhaps not surprisingly, these newly explained ideas were generally endorsed by fellow managers.

Whether this was due to a desire to conform and follow their peer group or because the ideas are more feasible for SMTEs is not resolved. However, several managers explained that these ideas seemed low impact on the guest experience, low investment and had potential to make 
large changes. Below are three of their ideas, representing their most collectively supported initiatives:

- Initial Welcome Introduction: While engaging guests on their initial walk through of the premises, staff briefly (5-15 minutes) highlight environmental efforts in addition to the original pertinent information to show guests they are making an effort and hope guests follow suit. For example, while showing off the bathroom, the popularity of the towel reuse program and the water saving shower heads would be emphasised.

- Feedback Cards: Cards located in guest rooms asking for additional ideas for saving water (and other environmental efforts) in the accommodation. This initiative would engage guests in the creation of solutions and may encourage them to use resources more efficiently if they are part of the 'solution.'

- Child Focused Messaging: Signs asking guests to use only the water they need directed towards children with the hope they will in turn influence their parents. This could also ensure the tone of the messages are more appropriate to the holiday experience.

\section{Stage Two: Guest Questionnaire}

Cluster analysis was performed and three distinct clusters were identified through segmenting the data based on guests' water use behaviour. To summarize, the largest cluster, cluster 1 ( $\mathrm{n}=$ 165), was generalized by a high effort to save water. Additionally, they scored highest for almost every intervention and message. Therefore, this cluster may represent the 'most conscientious', needing little encouragement to save water. However, differences between cluster 2 and 3 presented the most fascinating data. The second largest cluster, cluster 2 $(n=135)$, represented individuals with the lowest overall effort and, specifically, the least effort to stop taps from running which is typically considered a habitual behaviour (DEFRA, 2008). Combined with placing the highest level of importance on all services, it may be expected that they were disinterested in saving water. However, they responded with a moderate level of 
positivity towards initiatives and messages. Therefore, they appeared unaware of their impacts but also receptive to engaging in behaviour change initiatives and were labelled, 'overt users' due to the type of water use they displayed. This was in contrast to cluster 3 whom were labelled 'disengaged' as they appeared least likely to engage in initiatives.

Table 2 presents sample characteristics whilst Table 3 provides travel characteristics by cluster. Significant differences between clusters were observed between age; presence of children in the household; those visiting friends and relatives on their last overnight in tourism accommodation; the importance of all services (excluding 'en-suite bathrooms') on the booking process; and, overnight stays in tourism accommodation per year for business/work. Interestingly, the cluster 'overt users' reported a greater desire for all seven services than the other clusters.

[Insert Table 2 near here]

[Insert Table 3 near here]

The most frequently reported behaviour was 'I take one or less showers/baths per day,' while the lowest reported was 'I do not wait for the right temperature,' meaning taps and showers are allowed to run until they were hot or cold. All behaviours measured in this study showed significant differences between clusters. Table 4 presents behavioural data for each cluster in descending order by most frequently reported.

[Insert Table 4 near here] 
The general profile demonstrates that the 'most conscientious' cluster was the oldest group, with the least amount of households with children, visited friends and relatives least often during their last trip, placed the lowest importance on all seven services, and stay in tourism accommodation for business/work the least. This cluster also reported significantly higher effort to save water and greater effort for each of the eight behaviours.

The cluster, 'overt users' was characterized as the youngest, with the most amount of households with children present, having the most respondents visiting friends and relatives, placing the highest importance of all seven services on their last booking, and staying in tourism accommodation for business/work most frequently. They also reported the lowest general effort to save water in tourism accommodation and the lowest scores for four of the five behaviours related to running taps.

The third cluster, 'disengaged' was composed of individuals with a mean score between the others for age; households with children; respondents visiting friends and relatives; placing importance on services for their last booking; and, staying in tourism accommodation for business/work. Additionally, they reported general effort to save water in tourism accommodation between that of the other clusters. However, they reported the least effort for behaviours not related to running taps (towel reuse; green-certified businesses; shower instead of bath). The only exception was the tap related behaviour, 'I control water when showering,' where they reported the lowest effort.

\section{Initiatives and messaging}

Combining new ideas from SMTEs and previous ideas highlighted in this literature review, eight initiatives and five messages were presented to survey participants. Respondents indicated how each initiative would impact their experience. Impact on the guest experience was used here as it was the number one barrier to implementing initiatives stated by managers in stage 
one. These eight initiatives were designed to explore a diverse array of efforts (e.g. technologies, incentives, communication and engagement).

Five messages were evaluated on how likely they would encourage individuals to use less water. An effort was made to include a diversity of messages found in the literature review of this study (e.g. drought, climate change, child focused, standard message, use of psychological theory). A message of "Quack quack is duck for 'please save some water for me"” aimed to represent the SMTE recommendation to be 'fun' while targeting children. Table 5 provides responses by cluster, ranked in descending order by overall sample mean. Significant differences for each initiative and message were observed between clusters. Participants were also asked where messages would be best located to encourage them to reduce water use. The bathroom was the number one reported location and significant differences between bathroom, website, verbally and 'no message would be effective' between clusters were observed as seen in Table 6.

[Table 5 inserted near here]

[Table 6 inserted near here]

All clusters reported money-off vouchers and donations to charity would most positively impact their experience. For the 'most conscientious', this was followed by highlighting efforts in the initial welcome and then feedback cards. However, the other clusters ranked feedback cards above highlighting efforts in the initial welcome. Mean scores for both of these manager lead initiatives were above the initiative 'messages asking guests to help.' This was surprising as managers expressed the highest interest in messaging and, as evidenced previously in this paper, a substantial amount of previous literature has focused on changing signage. 
The 'most conscientious' cluster reported that every initiative would more positively impact their experience than other clusters. They also stated every message would encourage them to save water to a greater extent than the other two clusters. Mean scores for 'overt users' were between those of other clusters for every initiative except money-off vouchers which they ranked lowest. Following that trend, for encouragement from messaging, the 'overt users' cluster ranked between the other clusters for every message. Ranking lowest for all initiatives were the 'disengaged' cluster (except money-off vouchers where they ranked in between other clusters). This cluster also contained the highest number of individuals stating no message would be effective in changing their behaviour.

All clusters agreed that the most general message starting with 'Please promote...' would most encourage saving water. The child focused message developed from manager feedback ('Quack quack...') received the lowest score. While it is important to note that all respondents to the survey were adults and the message was meant to target children, due to the low score, this initiative would not be recommended with the tourism accommodation.

\section{Discussion}

Due to the low sample size (16), geographical limitations and convenience sampling of SMTE managers in stage one, generalizing results for all SMTEs would be unwise. However, promisingly, results did support several findings from the literature. For example, managers reported the greatest barrier was potentially negatively affecting the guest experience (Coles et al., 2016), followed by costs. No consensus was found on motivations for such efforts which would support findings from Fassin et al. (2011) and Font et al. (2014) that SMTEs have a variety of drivers for engaging in CSR. Additionally, managers were concerned about the length and type of messaging with guests as reported by Font et al. (2016) and Coles et al. (2016). 
While manager responses validated past literature, they also yielded two important new findings. First, participating managers reported many of the efforts previously explored in the literature to promote water efficiency behaviour were not viable within their current operations due to constraints related to their size. Importantly, donations to charity and money-off vouchers were deemed inappropriate to their operations due to financial constraints and a lack of technology and/or staffing to manage such complicated efforts. Instead, they offered three low resource intensive ideas not previously examined in the literature.

The subsequent guest questionnaires provided several novel findings as well. Most importantly, the majority of guests showed a willingness to exchange something for changing their water behaviour. Such an exchange should also consider competing factors for guests' behaviour (Shaw et al., 2013). Shove (2003) argues these competing factors are embedded in the needs and services of comfort, cleanliness and convenience. Here these needs and services were identified by managers. Certainly no guest should be expected to refrain from showering or brushing their teeth and instead this research has focused on guests using only what they need. Since guests were willing to exchange for their change in behaviour we therefore find the competing factors identified by Shove (2003) as helpful points in navigating this exchange and not necessarily impediments.

When viewed through the process of targeting audience segments, if resources are scarce, SMTEs focusing efforts on the 'overt users' cluster to maximize return on investment. That is, this group showed the lowest effort on tap related efforts (e.g. showering, sink use and inability to use dual flush toilets) which have been identified to be high water consumptive practices (UKWIR, 2014; South West Water, 2014). This group also showed a moderate level of positivity towards exchanging for a change in their behaviour. Additionally, targeting other clusters may provide lower returns as the 'most contentious' is likely to follow any reasonable appeals while the 'disengaged' are likely to ignore such requests all together. The 'overt users' cluster, as others, reported the highest positive impact from money-off vouchers and donations 
to charity. However, if SMTEs are unable to offer incentives due to limitations explained earlier, feedback cards and then engaging this cluster in conversation, perhaps during the initial welcome introduction, would have the next most positive impact on their experience. Since they reported letting taps run, an emphasis during any conversations on the accommodation's efforts to reduce water waste from taps (e.g. implementing water efficient shower heads, low flow toilets, promptly fixing leaks, etc.) would be recommended.

These results may also have theoretical implications for how SMTEs apply social marketing. Importantly, guests reported the greatest positive impact on their experience from those initiatives requiring the highest financial and logistical investment (e.g. money-off vouchers and donations to charity). This supported previous findings by Miao and Wei (2013) that guest behaviour in tourism accommodation is driven by hedonic motivation, needing rewards to facilitate such an exchange. Some larger hotel firms (e.g. Starwood and ACCOR) have already begun implementing such programs. Therefore, the financial constraints, lack of IT and staff to manage such programs, as identified by SMTE managers in this study and the literature (Ateljevic and Doorne, 2000; Dewhurst and Thomas, 2003), could represent a difficult hurdle for them to contend with larger competitors in changing guest behaviour. This may indicate that in some instances, larger firms have a competitive advantage over SMTEs in applying social marketing to change guest behaviour. However, as displayed by the guest questionnaire, lower investment options, specifically feedback cards and the initial welcome introduction, may still be viable options. Recent work by Warren, Becken and Coghlan (2016), published after this research was conducted, further the recommendation of implementing initial welcome introductions. In their study, they found persuasive communication, delivered throughout the tourism accommodation experience, significantly promoted pro-environmental behaviour by guests and generally increased guest satisfaction in a small tourism enterprise in Australia. Their work also recommends best practices in communicating to guests in this context. 
Several limitations to the study need further discussion. First, in stage one, due to the convenience sampling method and request for interviews through email of SMTE managers, it is possible that participants were self-selecting. While results supported several findings in other recent research, this limitation is clearly acknowledged and future research on the topic could increase sample sizes and use randomized a posteriori methods for segmenting their audience. As such, due to the limited geographical range and small sample size (16) of the current research, findings may not be applicable to all SMTEs. In stage two, the opportunity for an attitude-behaviour gap was possible. That is, claims that initiatives may positively impact the guest experience may not be true in practice. To minimize this concern most behavioural questions were adopted from previous literature and each scale was subject to a Cronbach's alpha test for reliability. Additionally, a social desirability bias may have also existed. To minimize this bias, online questionnaires were conducted, as opposed to face to face questionnaires, as Kreuter, Presser and Tourangeau (2008) find web based surveying reduces this issue. Additionally, within the survey instrument, comment sections were provided for each question to allow participants to further express their answers. Finally, a pilot survey was conducted to check for understanding and clarity of the instrument. However, despite these efforts, these phenomena may have been present in this study, as is true of any research of this nature, and are acknowledged as limitations.

\section{Conclusion}

This paper investigated the impact on guest experience of initiatives designed to promote water efficient behaviour within SMTEs. Businesses stated they were unable or unwilling to incorporate many of the initiatives previously examined in the academic literature, in particular money-off vouchers and donations to charity, due to limitations related to their size. Instead they contributed three new ideas: feedback cards; highlighting their environmental efforts during the initial welcome introduction; and, messaging focused on children. 
To examine how these ideas may impact the guest experience, a subsequent online questionnaire was administered. While recent literature has suggested many SMTEs avoid engaging with their guests to change behaviour and communicate their efforts (Coles et al., 2016; Font et al., 2016), here most guests reported positively towards participating in initiatives. To further understand how to target guests, cluster analysis was used with three distinct segments of water users emerging: 'most conscientious,' 'overt users' and 'disengaged.' Each cluster behaved significantly different with some more willing to engage in initiatives then others. The 'overt users' cluster showed the greatest promise for targeting with the goal of increasing return on investment. This was due to their type of behaviour, allowing taps to run, and responsiveness to engage in an exchange.

Results also showed guests reported the highest positive impact on their experience from those initiatives SMTEs stated were not viable due to financial and logistical limitations. Specifically, money-off vouchers and donations to charity were reported to have the greatest positive impact. Some larger firms (e.g. Starwood and ACCOR) have already begun implementing such programs. This may indicate, larger firms have a competitive advantage over SMTEs for applying social marketing to promote water efficiency. However, two initiatives deemed more appropriate by participating SMTEs (feedback cards and initial welcome introduction) represented more modestly acceptable opportunities for engaging the 'overt users' at low cost to the business.

Findings also have implications for future research. Importantly, the 'overt users' cluster reported the highest expectations for services on the tourism accommodation experience. Managers may therefore be advised to follow best practices supported by data driven research when engaging guests in initiatives to avoid scepticism as reported in Shang et al. (2009). However, SMTEs reported no previous exposure to findings from previous research efforts aiming to change guest behaviour. This was supported by observation from Coles et al. (2016) that many SMTEs avoid engaging guests. While Fassin et al. (2011) have identified that 
smaller firms may not need theory to have a strong grasp of CSR, it would appear there is a need here for more exposure to previous research findings for this particular aspect of CSR- engaging guests in changing their behaviour. This may be due to the delicate balance of messaging to guests (Coles et al., 2016; Font et al., 2016). Therefore, clearly more impact driven research, studies developed with practitioners where findings are made readily available to those intended to use them, with SMTEs, is needed in this area if tourism systems are to become more sustainable.

While the findings offer strong conceptual and practical recommendations for the use of social marketing to change guest behaviour by SMTEs, discrepancies between reported behavioural scores and those actually occurring are always possible in any study of this nature. Moreover, whilst managers offered anecdotal evidence that, for example, highlighting environmental efforts during the initial welcome introduction changed guest behaviour, no data exists to evidence this claim. Therefore, while this study focused on how initiatives would impact the guest experience, identified as the greatest barrier to implementation by managers in stage one of this research, further research, preferably experimental in design to combat the attitude-behaviour gap, is recommended to determine impacts from these initiatives on changing behaviour. Studies such as Warren, et al. (2016) aid in addressing this issue, through further research, perhaps specific to feedback card and SMTEs, would assist in creating more sustainable tourism systems.

\section{References}

Andreasen, A.R. (2002) The life trajectory of social marketing: some implications. Marketing Theory 3(3): 293-303.

Ateljevic, J. and Doorne, S. (2000) Staying within the fence: lifestyle entrepreneurship in tourism. Journal of Sustainable Tourism 8(5): 378-92.

Baca-Motes, K., Brown, A., Gneely, A., Kennan, E.A. and Nelson, L.D. (2013) Commitment and behaviour change: Evidence from the field. Journal of Consumer Research 39: 10701084. 
Barbour, R. (2007) Doing Focus Groups. London: Sage.

Barbour, R. (2013) Introducing Qualitative Research: A Students' Guide. London UK: Sage Publishing.

Barr, S., Shaw, G., Coles, T. and Prillwitz, J. (2010) "A holiday is a holiday": Practicing sustainability, home and away. Journal of Transport Geography 18: 474-481.

Blose, J.E., Mack, R.W. and Pitts, R.E. (2015) The influence of message framing on hotel guests' linen-reuse intentions. Cornell Hospitality Quarterly 56(2): 145-154.

Coles, T., Zschiegner, A.K. and Dinan, C. (2014) A cluster analysis of climate change mitigation behaviours among SMTEs. Tourism Geographies 16(3): 382-399.

Coles, T., Warren, N., Borden, D.S. and Dinan, C (2016) Business models among SMTEs: identifying attitudes to environmental costs and their implications for sustainable tourism. Journal of Sustainable Tourism. DOI: 10.1080/09669582.2016.1221414.

Condon, L. (2004) Sustainability and small to medium sized enterprises-How to engage them. Australian Journal of Environmental Education 20(1):57-67.

Corner, A. and Randall, A. (2011) 'Selling Climate Change? The limitations of social marketing as a strategy for climate change public engagement.' Global Environmental Change 21: 1005-014.

Dann, S. (2010) Redefining social marketing with contemporary commercial marketing definitions. Journal of Business Research 6(2): 147-153.

Drasgow, F. (1984) Scrutinizing psychological tests: measurement equivalence and equivalent relationships with external variables are the central issue. Psychological Bulletin 95: 134-35.

DEFRA (2009) Public understanding of sustainable water use in the home. Available at: http://randd.defra.gov.uk/Default.aspx?Menu=Menu\&Module=More\&Location=None\& ProjectID=16190\&FromSearch=Y\&Publisher $=1 \&$ SearchText=ev0503\&SortString=Proje ctCode\&SortOrder=Asc\&Paging=10\#Description [Accessed July 30, 2014].

Dewhurst, H. and Thomas, R. (2003) Encouraging sustainable business practices in a nonregulatory environment: a case study of small tourism firms in a UK National Park. Journal of Sustainable Tourism 11(4): 383-403.

Dinan, C. and Sargeant, A. (2000) Social marketing and sustainability: A planned approach to social change. Progress in Tourism and Hospitality Research 12(3): 1-14.

Dolnicar, S., Grün, B., Leisch, F. and Schmidt, K. (2013) Required sample sizes for data-driven market segmentation analyses in tourism. Journal of Travel Research 53(3): 296-306.

Dolnicar, S. and Grün, B. (2009) Environmentally friendly behaviour- can heterogeneity among individuals and contexts/ environments be harvested for improved sustainable management? Environment and Behaviour 41(5): 693-714.

Fassin, Y., Van Rossem, A., and Buelens, M. (2011) Small-Business Owner-Managers' Perceptions of Business Ethics and CSR-Related Concepts. Journal of Business Ethics 98: 425-53.

Font, X., Elgammal, I. and Lamond, I. (2016) Greenhushing: the deliberate under communicating of sustainability practices by tourism businesses. Journal of Sustainable Tourism. DOI: 10.1080/09669582.2016.1158829. 
Font, X., Garay, L., and Jones, S. (2014) Sustainability motivations and practices in small tourism enterprises in European protected areas. Journal of Cleaner Production. doi:10.1016/j.jclepro.2014.01.071

Franke, N., Reisinger, H. and Hoppe, D. (2009) Remaining within-cluster heterogeneity: A metaanalysis of the 'dark side' of clustering methods. Journal of Marketing Management 25(3-4): 273-293.

French, J., Blair-Stevens, C., McVey, D. and Merritt, R. (2010) Social Marketing and Public Health, Theory and Practice. Oxford: Oxford University Press.

Goldstein, N.J., Cialdini, R.B. and Griskevicius, V. (2008) A room with a viewpoint: Using social norms to motivate environmental conservation in hotels. Journal of Consumer Research 35(3): 472-482.

Gordon, R. (2012) Rethinking and re-tooling the social marketing mix. Australasian Marketing Journal 20(2): 122-126.

Gössling, S., Peeters, P., Hall, M., Ceron, J-P., Dubois, G., Lehman, L.V. and Scott, D. (2012) Tourism and water use: Supply, demand, and security. An international review. Tourism Management 33(1): 1-15.

Gössling, S., Hall, C.M. and Scott, D. (2015) Tourism and Water. Bristol, UK: Channel View Publications.

Hair, J.F., Black, W.C., Babin, B.J. and Anderson, R.E. (2010) Multivariate Data Analysis. New Jersey, USA: Pearson Education, Inc.

Hall, M.C. (2014) Tourism and Social Marketing. London, Routledge.

Kreuter, F., Presser, S., and Tourangeau, R. (2008) Social desirability bias in CATI, IVR, and Web surveys the effects of mode and question sensitivity. Public Opinion Quarterly 72(5): 847-865.

Lee, S. and Oh, H. (2014) Effective communication strategies for hotel guests' green behaviour. Cornell Hospitality Quarterly. 55(1): 52-63.

Mazzocchi, M. (2008) Statistics for Marketing and Consumer Research. London, UK: Sage.

Mair, J. and Bergin-Seers, S. (2010) The effect of interventions on the environmental behaviour of Australian motel guests. Tourism and Hospitality Research, 10(4): 255-268.

McKenzie-Mohr, D., Lee, N.R., Shultz, P.W. and Kotler, P. (2012) Social Marketing to Protect the Environment: What Works. London, England: SAGE Publications, Inc.

Miao, L. and Wei, W. (2013) Consumers' pro-environmental behaviour and the underlying motivations: A comparison between household and hotel settings. International Journal of Hospitality Management 32: 102-112.

Molina-Azorín, J. F., and Font, X. (2016) Mixed methods in sustainable tourism research: an analysis of prevalence, designs and application in JOST (2005-2014). Journal of Sustainable Tourism 24(4): 549-573.

Morsing, M. and Perrini, F. (2009) CSR in SMEs: do SMEs matter for the CSR agenda? Business Ethics: A European Review 18(1): 1-6.

OFWAT (2011) Push, pull, nudge: How can we help consumers save water, energy and money? Available at: www.ofwat.gov.uk [Accessed July 30, 2014]. 
O'Neill and Siegelbaum, and the RICE Group. (2002) Hotel water conservation: A Seattle demonstration. Seattle, WA: Resources Conservation Section, Seattle Public Utilities.

Reese, G., Loew, K. and Steffgen, G. (2014) Towel less: Social norms enhancing proenvironmental behaviour in hotels. Journal of Social Psychology 154: 97-100.

Schultz, W.P., Khasian, A.M. and Zaleski, A.C. (2008) Using normative social influence to promote conservation among hotel guests. Social Influence 3(1): 4-23.

Scott, D., Peeters, P. and Gössling, S. (2010) Can tourism deliver its "aspirational" greenhouse gas emission reduction targets? Journal of Sustainable Tourism 18(3): 393-408.

Shang, J., Basil, D.Z. and Wymer, W. (2010) Using social marketing to enhance hotel reuse programs. Journal of Business Research 63: 166-172.

Shaw, G., Barr, S. and Wooler, J. (2013) The application of social marketing to tourism (p.54-64). In McCabe, S. (Eds.) (2013) The Routledge Handbook of Tourism Marketing. London, Taylor and Francis Ltd.

Shove, E. (2003) Users, technology and expectations of comfort, cleanliness and convenience. Innovation 16(2): 193-206.

South West Water (2014): Draft Water Resources Management Plan, 2015-2040. Available at:https://www.southwestwater.co.uk/media/pdf/4/7/South_West_Water_Draft_Water _Resources_Management_Plan_March_2013.pdf . [Accessed May 15, 2014].

Storey, D.J. (1994) Understanding the Small Business Sector. London: Thomson Learning.

Truong, D.V. and Hall, M.C. (2013) Social marketing and tourism: What is the evidence? Social Marketing Quarterly 19(2): 110-135.

UK Office for National Statistics (2015) Retrieved 11'th November, 2016, from: http://www.ons.gov.uk/ons/rel/lifetables/national-life-tables/2010---2012/sty-factsabout-le.html

UKWIR (UK Water Industry Research) (2014) Understanding customer behaviour for water demand forecasting. Report Ref. No. 14/WR/01/14. UK Water Industry Research Limited, London.

Warren, C., Becken, S. and Coghlan, A. (2016) Using persuasive communication to co-create behavioural change- engaging with guests to save resources at tourist accommodation facilities. Journal of Sustainable Tourism. DOI: 10.1080/09669582.2016.1247849 
Figure 1: Type of accommodations recorded in South West Water customer database.

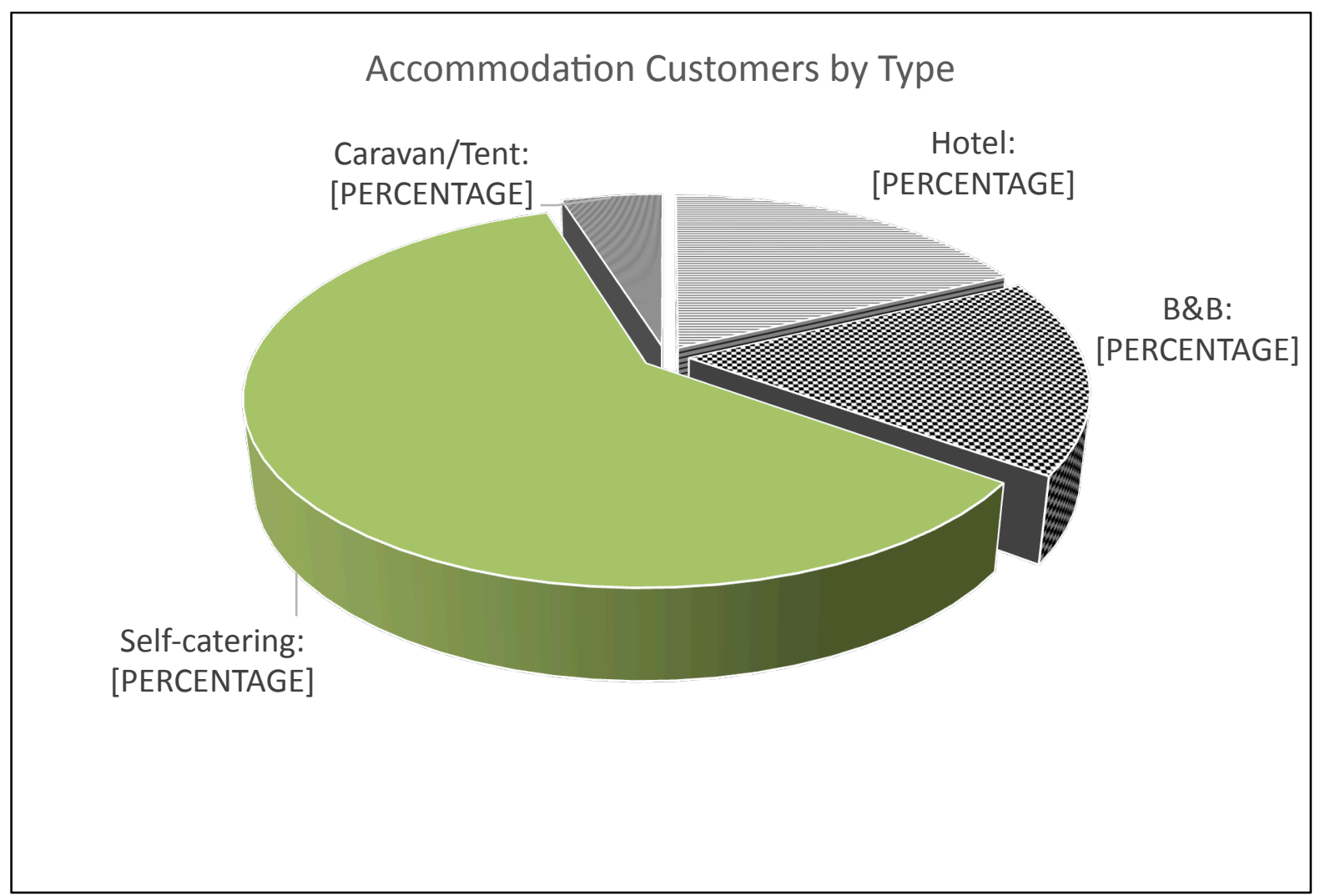

Source: authors 
Table 1: Key information concerning participating accommodation managers in semistructured interviews.

\begin{tabular}{|l|l|l|l|l|}
\hline Business & $\begin{array}{l}\text { Accommodation } \\
\text { Type }\end{array}$ & $\begin{array}{l}\text { Accommodation } \\
\text { Size }\end{array}$ & $\begin{array}{l}\text { GTBS } \\
\text { Level^ }\end{array}$ & Star Rating \\
\hline T1 & Tent/Caravan & Micro & Gold & N/A \\
\hline T2 & Tent/Caravan & Small & N/A & N/A \\
\hline BB1 & B\&B & Micro & N/A & N/A \\
\hline BB2 & B\&B & Micro & Gold & N/A \\
\hline BB3 & B\&B & Micro & N/A & 3 \\
\hline H1 & Hotel & Small & N/A & 3 \\
\hline H2 & Hotel & Micro & Silver & N/A \\
\hline H3 & Hotel & Medium & N/A & $3-4$ \\
\hline SC1 & Self-catering & Micro & N/A & N/A \\
\hline SC2 & Self-catering & Micro & Gold & 5 \\
\hline SC3 & Self-catering & Micro & N/A & 4 \\
\hline SC4 & Self-catering & Micro & Gold & 5 \\
\hline SC5 & Self-catering & Micro & Gold & 5 \\
\hline SC6 & Self-catering & Micro & N/A & N/A \\
\hline SC7 & Self-catering & Micro & N/A & N/A \\
\hline SC8 & Self-catering & Micro & N/A & 4 \\
\hline
\end{tabular}

${ }^{\wedge}$ Green Tourism Business Scheme (GTBS) Level indicates regional certification for environmental efforts.

Source: authors 
Table 2: Characteristics of the sample by cluster.

\begin{tabular}{|c|c|c|c|}
\hline Characteristics & $\begin{array}{c}\text { Most } \\
\text { conscientious }\end{array}$ & Overt users & Disengaged \\
\hline$n$ & 165 & 135 & 108 \\
\hline \multicolumn{4}{|l|}{ Gender } \\
\hline Male & $44.8 \%$ & $45.9 \%$ & $36.1 \%$ \\
\hline Female & $55.2 \%$ & $54.1 \%$ & $63.9 \%$ \\
\hline \multicolumn{4}{|l|}{ Age $^{a}$} \\
\hline $18-19$ & $3 \%$ & $3.7 \%$ & $7.4 \%$ \\
\hline $20-24$ & $8.5 \%$ & $11.1 \%$ & $12 \%$ \\
\hline $25-29$ & $11.5 \%$ & $28.1 \%$ & $19.4 \%$ \\
\hline $30-34$ & $15.2 \%$ & $14.1 \%$ & $18.5 \%$ \\
\hline $35-44$ & $20 \%$ & $17.8 \%$ & $17.6 \%$ \\
\hline $45-59$ & $21.2 \%$ & $20 \%$ & $16.7 \%$ \\
\hline $60-64$ & $11.5 \%$ & $2.2 \%$ & $1.9 \%$ \\
\hline $65-74$ & $7.9 \%$ & $2.2 \%$ & $5.6 \%$ \\
\hline$>74$ & $1.2 \%$ & $0.7 \%$ & $0.9 \%$ \\
\hline Average age ${ }^{\mathrm{b}}$ & 42.3 & 36.18 & 36.5 \\
\hline \multicolumn{4}{|l|}{ Total household income+ } \\
\hline$<£ 9,999$ & $7.3 \%$ & $7.4 \%$ & $8.3 \%$ \\
\hline$£ 10,000-£ 19,999$ & $18.8 \%$ & $18.5 \%$ & $18.5 \%$ \\
\hline$£ 20,000-£ 29,999$ & $14.5 \%$ & $18.5 \%$ & $16.7 \%$ \\
\hline$£ 30,000-£ 39,999$ & $17.6 \%$ & $20 \%$ & $18.5 \%$ \\
\hline$£ 40,000-£ 49,999$ & $14.5 \%$ & $11.9 \%$ & $13 \%$ \\
\hline$£ 50,000-£ 74,999$ & $12.1 \%$ & $11.1 \%$ & $15.7 \%$ \\
\hline$£ 75,000-£ 100,000$ & $3.6 \%$ & $7.4 \%$ & $0.9 \%$ \\
\hline$>£ 100,000$ & $3 \%$ & $2.2 \%$ & $0.9 \%$ \\
\hline Prefer not to say & $8.5 \%$ & $3 \%$ & $7.4 \%$ \\
\hline Average income ${ }^{\wedge}$ & $£ 34,060$ & $£ 36,315$ & $£ 31,481$ \\
\hline \multicolumn{4}{|l|}{ Highest educational qualification } \\
\hline GCSE/NVQ & $24.8 \%$ & $25.2 \%$ & $26.9 \%$ \\
\hline A/AS Level/GNVG & $33.9 \%$ & $25.2 \%$ & $25 \%$ \\
\hline Bachelor's Degree & $28.5 \%$ & $30.4 \%$ & $33.3 \%$ \\
\hline Master's & $9.1 \%$ & $13.3 \%$ & $13.9 \%$ \\
\hline Doctorate & $3.6 \%$ & $5.9 \%$ & $0.9 \%$ \\
\hline Average number of individuals in household & 2.81 & 3.06 & 2.94 \\
\hline Presence of children in household ${ }^{\mathrm{a}}$ & $36 \%$ & $53 \%$ & $41 \%$ \\
\hline \multicolumn{4}{|l|}{ Housing situation } \\
\hline Home owned outright & $24.2 \%$ & $22.2 \%$ & $25 \%$ \\
\hline Home owned with mortgage or loan & $36.4 \%$ & $27.4 \%$ & $31.5 \%$ \\
\hline Shared ownership & $1.8 \%$ & $1.5 \%$ & $0 \%$ \\
\hline Let from council & $12.7 \%$ & $15.6 \%$ & $11.1 \%$ \\
\hline Let from private landlord or letting agency & $18.8 \%$ & $27.4 \%$ & $22.2 \%$ \\
\hline Other & $6.1 \%$ & $5.9 \%$ & $10.2 \%$ \\
\hline \multicolumn{4}{|l|}{ Water metrics } \\
\hline With water meter in the home & $52 \%$ & $44 \%$ & $54 \%$ \\
\hline Differences in water company+ & & - & - \\
\hline \multicolumn{4}{|l|}{ Occupation } \\
\hline Higher managerial, administrative or professional & $8.5 \%$ & $9.6 \%$ & $9.3 \%$ \\
\hline Intermediate managerial, administrative or professional & $20 \%$ & $20.7 \%$ & $17.6 \%$ \\
\hline $\begin{array}{c}\text { Supervisory or clerical and junior managerial, administrative or } \\
\text { professional }\end{array}$ & $30.9 \%$ & $28.9 \%$ & $29.6 \%$ \\
\hline Skilled manual worker & $10.9 \%$ & $20 \%$ & $12 \%$ \\
\hline Semi and unskilled manual worker & $4.2 \%$ & $10.4 \%$ & $10.2 \%$ \\
\hline Casual or non-worker & $25.5 \%$ & $10.4 \%$ & $21.3 \%$ \\
\hline
\end{tabular}

${ }^{\mathrm{a}}$ Indicates a significant difference between clusters using a Kruskal-Wallis H test or Mann-Whitney U test (p<0.05)

${ }^{\mathrm{b}}$ Estimated using a life expectancy of 85.65 (UK Office for National Statistics, 2015)

+ Excluded individuals that stated 'do not know' or 'prefer not to say' during Kruskal-Wallis $\mathrm{H}$ test

$\wedge$ Estimated using an upper limit of $£ 150,000$

Source: authors 
Table 3: Travel characteristics by cluster.

\begin{tabular}{|c|c|c|c|}
\hline Characteristics & $\begin{array}{c}\text { Most } \\
\text { conscientious }\end{array}$ & $\begin{array}{l}\text { Overt } \\
\text { users }\end{array}$ & Disengaged \\
\hline \multicolumn{4}{|l|}{ Type of accommodation } \\
\hline Hotel & $48.5 \%$ & $49.6 \%$ & $53.7 \%$ \\
\hline$B \& B$ & $15.2 \%$ & $20 \%$ & $13.9 \%$ \\
\hline Self-catering & $13.3 \%$ & $8.9 \%$ & $13 \%$ \\
\hline Campsite/ Caravan Park & $23 \%$ & $21.5 \%$ & $19.4 \%$ \\
\hline \multicolumn{4}{|l|}{ Motivation for travel ${ }^{\mathrm{b}}$} \\
\hline To visit friends and relatives ${ }^{a}$ & $22.4 \%$ & $39.3 \%$ & $23.1 \%$ \\
\hline Holiday & $76.4 \%$ & $67.4 \%$ & $80.6 \%$ \\
\hline Business or for work & $4.8 \%$ & $10.4 \%$ & $6.5 \%$ \\
\hline \multicolumn{4}{|c|}{ Mean score of services' importance on last booking* } \\
\hline Swimming pool ${ }^{\mathrm{a}}$ & 2.29 & 2.93 & 2.38 \\
\hline En-suite bathroom & 3.89 & 4.01 & 3.74 \\
\hline Spa $^{\mathbf{a}}$ & 2.05 & 2.67 & 2.31 \\
\hline Separate shower and bath ${ }^{a}$ & 2.8 & 3.13 & 2.68 \\
\hline Fresh linen daily ${ }^{a}$ & 3.13 & 3.7 & 3.18 \\
\hline Fresh towel(s) daily ${ }^{a}$ & 3.29 & 3.81 & 3.33 \\
\hline Luxury shower ${ }^{\mathbf{a}}$ & 2.74 & 3.21 & 2.74 \\
\hline \multicolumn{4}{|c|}{ Nights stayed in tourism accommodation per year for: } \\
\hline \multicolumn{4}{|l|}{ Holiday } \\
\hline $0-5$ & $35.2 \%$ & $38.5 \%$ & $25.9 \%$ \\
\hline $5-10$ & $25.5 \%$ & $28.9 \%$ & $29.6 \%$ \\
\hline $10-15$ & $15.2 \%$ & $18.5 \%$ & $24.1 \%$ \\
\hline $15-20$ & $9.7 \%$ & $10.4 \%$ & $15.7 \%$ \\
\hline Over 20 & $14.5 \%$ & $3.7 \%$ & $4.6 \%$ \\
\hline Average $^{\wedge}$ & 9.65 & 8.09 & 9.68 \\
\hline \multicolumn{4}{|l|}{ Business/work ${ }^{a}$} \\
\hline $0-5$ & $90.9 \%$ & $71.1 \%$ & $81.5 \%$ \\
\hline $5-10$ & $3.6 \%$ & $20 \%$ & $11.1 \%$ \\
\hline $10-15$ & $3.6 \%$ & $6.7 \%$ & $4.6 \%$ \\
\hline $15-20$ & $1.2 \%$ & $0.7 \%$ & $2.8 \%$ \\
\hline Over 20 & $0.6 \%$ & $1.5 \%$ & $0.0 \%$ \\
\hline Average $^{\wedge}$ & 3.35 & 4.57 & 3.94 \\
\hline
\end{tabular}

${ }^{\mathrm{a}}$ Indicates a significant difference between clusters using a Kruskal-Wallis H test or Mann-Whitney U test $(\mathrm{p}<0.05)$

${ }^{\mathrm{b}}$ Question allowing multiple responses (e.g. tick all that apply)

* Items were measured on a scale from 1 (very unimportant) to 5 (very important)

$\wedge^{\wedge}$ Calculated with an upper limit of 25 nights per year

Source: authors 
Table 4: Mean scores of water efficiency behaviour at home and in tourism accommodation by cluster.

\begin{tabular}{|c|c|c|c|c|}
\hline Item & $\overline{\mathrm{X}}$ & $\begin{array}{c}\text { Most } \\
\text { conscientious }\end{array}$ & $\begin{array}{l}\text { Overt } \\
\text { users }\end{array}$ & Disengaged \\
\hline $\begin{array}{l}\text { Overall effort to save water in tourism } \\
\text { accommodation }\end{array}$ & 3.06 & 3.56 & 2.64 & 2.81 \\
\hline Tourism accommodation behaviours+ & & & & \\
\hline I take one or less showers/baths per day ${ }^{\mathrm{Ra}}$ & 3.72 & 4.17 & 2.84 & 4.16 \\
\hline I turn off the tap when brushing teeth ${ }^{\mathrm{Ra}}$ & 3.61 & 4.23 & 2.35 & 4.22 \\
\hline I take efficient showers ${ }^{R a}$ & 3.51 & 4.07 & 2.73 & 3.64 \\
\hline $\begin{array}{l}\text { If offered, I participate in towel reuse } \\
\text { schemes }^{\mathrm{a}}\end{array}$ & 3.47 & 3.96 & 3.16 & 3.12 \\
\hline I shower instead of bath to save water ${ }^{a}$ & 3.25 & 4.24 & 2.94 & 2.1 \\
\hline I control water when showering ${ }^{a}$ & 3.07 & 3.56 & 2.78 & 2.69 \\
\hline I prefer certified green businesses ${ }^{a}$ & 2.71 & 2.85 & 2.73 & 2.47 \\
\hline I do not wait for the right temperature ${ }^{\mathrm{Ra}}$ & 2.51 & 2.65 & 2.27 & 2.63 \\
\hline
\end{tabular}

${ }^{\varphi}$ Items measured on a scale from 0 (I make no effort to save) to 6 (I make every effort to save)

${ }^{a}$ Indicates a statistically significant difference between clusters using a Kruskal-Wallis H test $(p<0.05)$

${ }^{\mathrm{R}}$ Item has been reverse coded

+ Items measured on a scale from 1 (never) to 5 (always)

Source: authors 
Table 5: Mean scores of the impact on the guest experience from behaviour change initiatives and messaging.

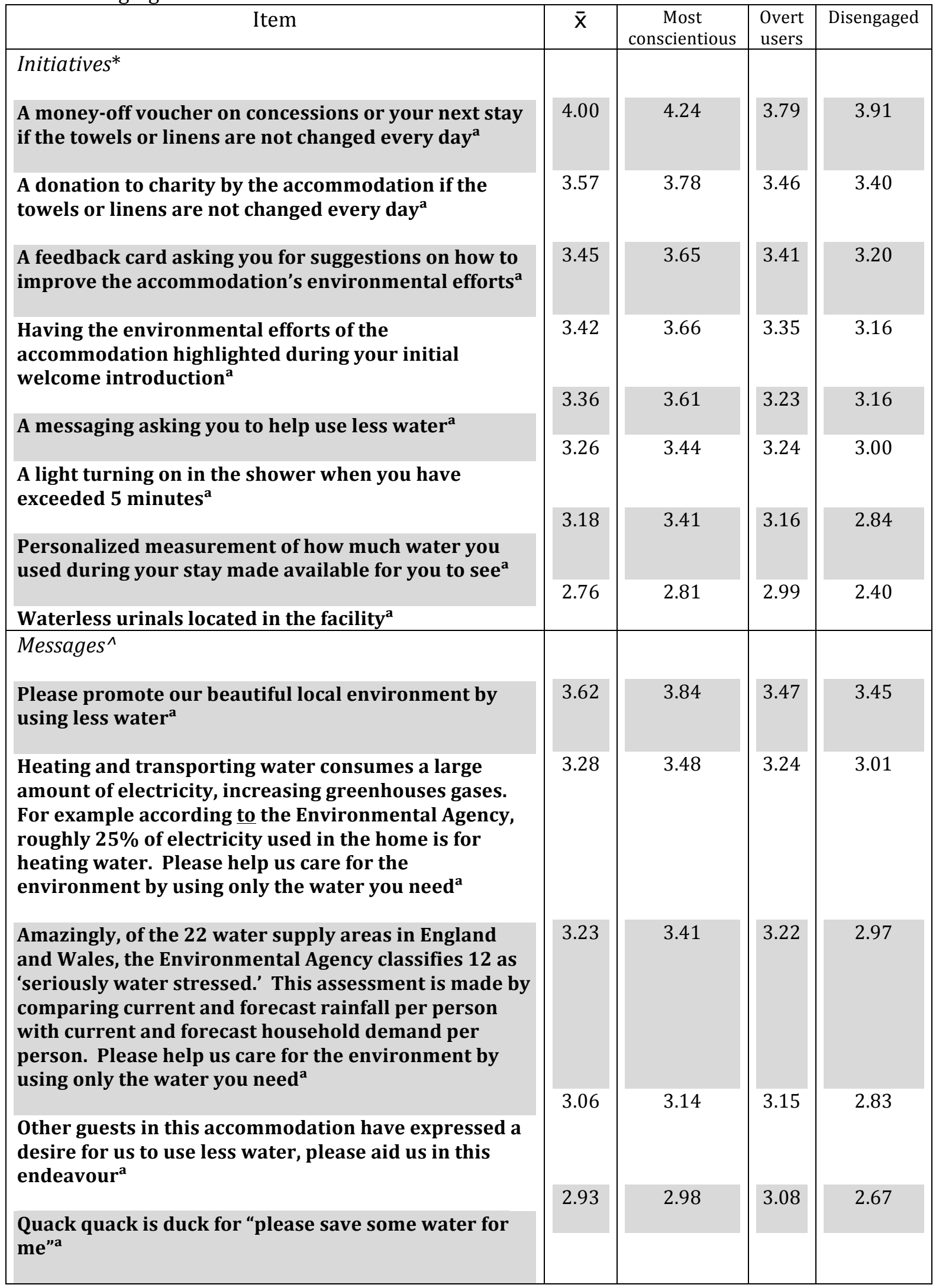

*Items measured on a scale from 1 (very negatively) to 5 (very positively).

${ }^{a}$ Indicates a statistically significant difference between clusters using a Kruskal-Wallis $\mathrm{H}$ test $(\mathrm{p}<0.05)$

$\wedge$ Items measured on a scale from 1 (none) to 5 (very much)

Source: authors 
Table 6: Reported location where messages would have a high impact on behaviour.

\begin{tabular}{|l|r|r|r|}
\hline Location & Most conscientious & Overt users & \multicolumn{1}{|c|}{ Disengaged } \\
\hline Bathroom $^{\mathbf{a}}$ & $84 \%$ & $68 \%$ & $72 \%$ \\
\hline Welcome packet & $40 \%$ & $44 \%$ & $44 \%$ \\
\hline Website $^{\mathbf{a}}$ & $28 \%$ & $20 \%$ & $16 \%$ \\
\hline Verbally $^{\mathbf{a}}$ & $13 \%$ & $24 \%$ & $5 \%$ \\
\hline Email & $16 \%$ & $14 \%$ & $1 \%$ \\
\hline Phone & $6 \%$ & $7 \%$ & $9 \%$ \\
\hline $\begin{array}{l}\text { None, 'no messages } \\
\text { would be effective'a }\end{array}$ & $4 \%$ & $8 \%$ & \\
\hline
\end{tabular}

${ }^{\mathrm{a}}$ Indicates a significant difference between clusters using a Kruskal-Wallace H test $(\mathrm{p}<0.05)$

Source: authors 